\title{
Reply to: doi:10.1007/s00464-013-2958-8: Re: Prospective randomized clinical trial comparing laparoscopic cholecystectomy and hybrid natural orifice transluminal endoscopic surgery (NOTES) (NCT00835250)
}

\author{
Do we know the correct sample size?
}

\author{
José Noguera \\ Received: 23 February 2013/Accepted: 20 March 2013/Published online: 30 April 2013 \\ (C) Springer Science+Business Media New York 2013
}

I have read with interest the comments by Dr. Carlson [1] about our study [2] and I want to thank him for his interest in improving the quality of surgical investigations and Surgical Endoscopy.

When we designed our noninferiority pilot study, the EAES recommendations had been cited in order to perform safer surgical studies in the field of surgical innovative techniques [3]. The first problem with the design of a pilot study is to know the correct sample size [4], i.e., how many patients you must enroll to yield some valid information.

With wide experience in the animal laboratory with training on the use of flexible endoscopy and the cholecystectomy technique, a lower number of animals may be enough to know if we have some technical problems in order to develop the procedure in humans. It is very difficult to know the correct sample size in these situations, but when we enrolled 40 patients to undergo a flexible endoscope approach in the context of a pilot study (20 transvaginal, 20 transumbilical), we think we can reach some conclusions about the safety and the reproducibility of the procedure.

This study offers to the community the opportunity to continue this kind of study in larger groups of patients with a multicenter design. Currently, we have some clinical series with the data on NOTES from multicenter registers (European, German, and Latin American), and we are now in the fifth step of the EAES recommendations: "implementation along with monitoring."

If our conclusions sound too categorical, we apologize for the style of our redaction, but with our results we conclude that the innovative approach with the flexible endoscope through a natural orifice is as safe as laparoscopy in controlled groups, and we promote its expanded clinical use with continuous monitoring of its security and effectiveness.

I want to use this opportunity to thank the commendable work of the reviewers, although we can find some disgruntled opinions.

Disclosures Dr. José Noguera has no conflicts of interest or financial ties to disclose.

\section{References}

1. Carlson MA (2013) Prospective randomized clinical trial comparing laparoscopic cholecystectomy and hybrid natural orifice transluminal endoscopic surgery (NOTES) (NCT00835250). Surg Endosc 27. doi:10.1007/s00464-013-2958-8

2. Noguera JF, Cuadrado A, Dolz C, Olea JM, Garcia JC (2012) Prospective randomized clinical trial comparing laparoscopic cholecystectomy and hybrid natural orifice transluminal endoscopic surgery (NOTES) (NCT00835250). Surg Endosc 26:3435-3441

3. Neugebauer EA, Becker M, Buess GF, Cuschieri A, Dauben HP, Fingerhut A, Fuchs KH, Habermalz B, Lantsberg L, Morino M, Reiter-Theil S, Soskuty G, Wayand W, Welsch T, European Association for Endoscopic Surgery (EAES) (2010) EAES recommendations on methodology of innovation management in endoscopic surgery. Surg Endosc 24:1594-1615

4. Friede T, Kieser M (2011) Sample size reassessment in noninferiority trials. Internal pilot study designs with ANCOVA. Methods Inf Med 50:237-243

\footnotetext{
J. Noguera $(\square)$

Department of Surgery, Hospital General Universitario de

Valencia, C/ Tres Cruces, n ${ }^{\circ}$ 2, 46014 Valencia, Spain

e-mail: drjfnoguera@hotmail.com
} 